\title{
Ultrastructure of Testes of Ceraeochrysa claveri (Neuroptera: Chrysopidae) After Exposure to Azadirachtin and Pyriproxyfen
}

\author{
Ana Silvia Gimenes Garcia ${ }^{1}$, Elton Luiz Scudeler ${ }^{1}$, Daniela Carvalho dos Santos ${ }^{1,2}$ \\ 1. Laboratory of Insects, Department of Morphology, Institute of Biosciences of Botucatu, UNESP, \\ Botucatu, Brazil. \\ 2. Electron Microscopy Center, Institute of Biosciences of Botucatu, UNESP, Botucatu, Brazil.
}

Insects of Chrysopidae family are predators found in several crops of economic interest and play an important role in biological control of pests. Alternative methods of control also include the use of plant extracts such as Azadirachtin. However, the use of synthetic insecticides, such as Pyriproxyfen, may interfere with the life cycle of natural enemies and consequently biological control of pests.

Considering the importance of this insect and based on ultrastructural analyzes of his testes, we intend to evaluate the effect of the ingestion of azadirachtin and pyriproxyfen on the morphology of this organ. Ceraeochrysa claveri larvae were fed with Diatraea saccharalis eggs treated with azadirachtin (AzaMax ${ }^{\circledR}$, at concentrations 12 and 36mg a.i./L) and pyriproxyfen (Tiger 100 EC®, at concentrations 50 and $100 \mathrm{mg}$ a.i./L), besides the control group, treated with distilled water. The testes were obtained from adult insects, fixed in Karnovsky's solution and processed for transmission electron microscopy analysis.

The ultrastructural analysis revealed that $C$. claveri adult testes present mostly cysts containing spermatids and spermatozoa, with slightly elongate nucleus and the region of the flagellum composed by the axonema, whose arrangement of microtubules is $9+9+2$, in addition to two mitochondrial derivatives that surround it. The treated insects presented higher numbers of cysts at less developed stages, such as spermatids and discrete spacing between the cysts was observed when compared to the control group. The cellular tunic surrounding the testis was quite irregular and vacuolated at the higher dosages of the two insecticides. The results point to a delay in the spermatogenesis process and possible reduction in the gamete number, which could harm the perpetuation of this insect in the environmental.

Pyriproxyfen is known to act primarily by blocking the metamorphosis of adult larvae, as well as affecting reproduction, reducing fertility and fertility [1]. The lack of studies demonstrating the morphological effects of this insecticide leads us to conduct studies to identify the damage caused by this insecticide to the testes of this non-target insect, as we can observe in the results described above. The toxic effects of azadirachtin have been reported in several investigations involving reproductive aspects of insects [2-5]. One of these studies shows a direct action of azadirachtin on testicular membranes, blocking spermatocyte development in Mamestra brassicae [6]. Another study using a radiolabeled azadirachtin derivative in various tissues reports that $94 \%$ of this compound interacted with testicular membranes [4]. In addition, azadirachtin used at high concentrations may inhibit cyst formation around spermatogonia and therefore spermatocyte development has been impaired. Azadirachtin also causes disintegration of the testicular epithelium, spermatid degeneration and sperm bundles and preferentially binds to one of the sperm tail components [2-4].

We conclude that both insecticides are harmful to the perpetuation of this species, but additional studies have been executed to complement these results [7]. 
References:

[1] M. Jindra et al., Arch. Insect Biochem. Physiol. 2019, p.1

[2] N. Desneux et al., Annu. Rev. Entomol. 52 (2007), p. 81.

[3] N.A. Ghazawi et al., J. Orthopt. Res. 16 (2007), p. 57.

[4] A.J. Nisbet et al., Insect Biochem. Molec. Biol. 25 (1995), p. 551.

[5] D.V. Tayade, Biosci. Discov. 3 (2012), p. 79.

[6] T. Shimizu, Entomol. Exp. Appl. 46 (1988), p. 197.

[7] The authors acknowledge funding from Coordenação de Aperfeiçoamento de Pessoal de Nível Superior - Brasil (CAPES) - Código de Financiamento 001 e Fundação de Amparo à Pesquisa do Estado de São Paulo (FAPESP) - processos 2017/09901-1 e 2017/151202.
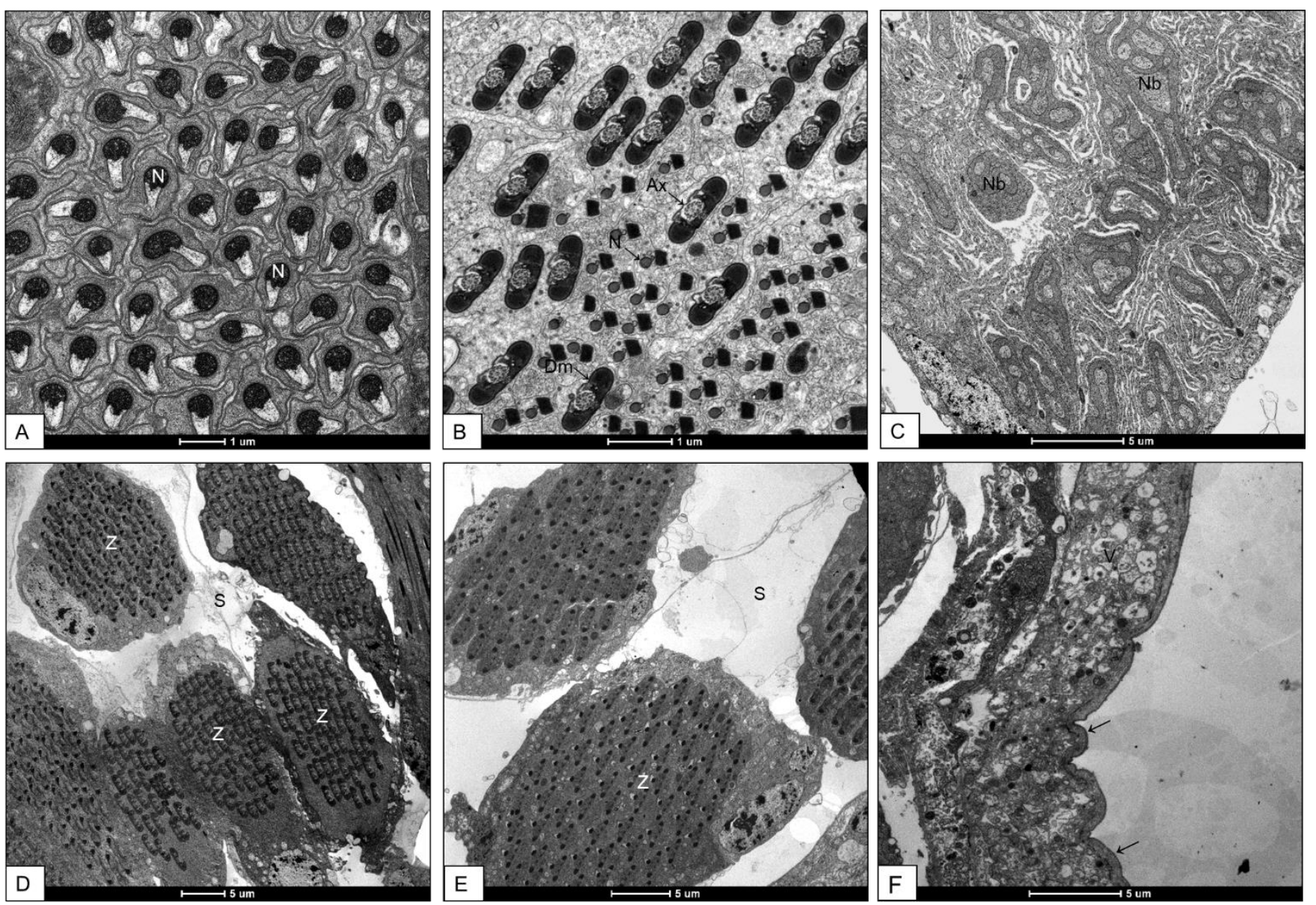

Figure 1: Photomicrographs in Transmission Electron Microscope. A. Spermatids nucleus (N) of control group. B. Control group spermatozoa presenting axonema (Ax), mitochondrial derivatives $(\mathrm{Dm})$ and nucleus $(\mathrm{N})$. C. Beginning of nebenkern formation $(\mathrm{Nb})$ in insect treated with $12 \mathrm{mg}$ Azamax. D. Spacing (S) between cysts of spermatozoa (Z) in treatment with $12 \mathrm{mg}$ Azamax. E. Treatment with 36mg Azamax leading to spacing (S) between the cysts of spermatozoa (Z). F. Irregularities in the external tunic (arrows) of insect treated with Tiger 100mg, in addition to vacuolation of cytoplasm (V). 